\title{
OPTICAL PLANKTON IMAGING AND ANALYSIS SYSTEMS FOR OCEAN OBSERVATION
}

\author{
Michael E. Sieracki ${ }^{(1)}$, Mark Benfield ${ }^{(2)}$, Allen Hanson ${ }^{(3)}$, Cabell Davis ${ }^{(4)}$, Cynthia H. Pilskaln ${ }^{(5)}$, David \\ Checkley $^{(6)}$, Heidi M. Sosik ${ }^{(4)}$, Carin Ashjian ${ }^{(4)}$, Phil Culverhouse ${ }^{(7)}$, Robert Cowen ${ }^{(8)}$, Rubens Lopes ${ }^{(9)}$, \\ William Balch ${ }^{(1)}$, Xabier Irigoien ${ }^{(10)}$ \\ (1) Bigelow Laboratory for Ocean Science, 180 McKown Point Road, W. Boothbay Harbor, Maine, 04538 USA, \\ Email: msieracki@bigelow.org, bbalch@bigelow.org \\ (2) Louisiana State University, Department of Oceanography \& Coastal Sciences, 2179 Energy, Coast \& Environment \\ Building, Baton Rouge, LA 70803 USA, Email: mbenfie@lsu.edu \\ ${ }^{(3)}$ Computer Vision Laboratory, Computer Science Department, University of Massachusetts, 140 Governors Drive, \\ Amherst, MA 01003 USA, Email: hanson@cs.umass.edu \\ (4) Woods Hole Oceanographic Institution, Biology Department, MS33, Woods Hole, MA 02453 USA, \\ Email: cdavis@whoi.edu; hsosik@whoi.edu; cashjian@whoi.edu \\ (5) University of Massachusetts Dartmouth, 706 South Rodney French Blvd., New Bedford, MA 02744 USA, \\ cpilskaln@umassd.edu \\ (6) Scripps Institute of Oceanography, UC (University of California) San Diego, 9500 Gilman Drive, La Jolla, CA \\ 92093 USA, Email: dcheckley@ucsd.edu \\ (7) Centre for Robotics \& Neural Systems, University of Plymouth, A311 Portland Square, Plymouth PL4 8AA \\ United Kingdom, Email: pculverhouse@plymouth.ac.uk \\ ${ }^{(8)}$ Rosenstiel School of Marine \& Atmospheric Science, 4600 Rickenbacker Causeway, University of Miami, \\ Miami, FL 33149 USA, Email: rcowen@rsmas.miami.edu \\ (9) Instituto Oceanografico, Universidade de Sao Paulo, Praca do Oceanografico 191, 05508-120 Sao Paulo, Brasil, \\ Email: rubens@usp.br \\ ${ }^{(10)}$ AZTI - Tecnalia / Marine Research Division, Herrera kaia portualdea z/g 20110 Pasaia (Gipuzkoa) Spain, \\ Email: xirigoien@azti.es
}

\begin{abstract}
Digital images of suspended particles in aquatic systems can reveal abundances, size spectra, and biomass distributions of planktonic organisms and non-living particles. Modern imaging systems are capable of recording the contents of defined volumes of water at high rates. In response to the need to analyze large image datasets, image analysis software and hardware are emerging as powerful tools for identifying the contents of images. Morphology combined with intrinsic image features can be used to identify phytoplankton and zooplankton organisms to genus in many cases. Moreover, many harmful algal species can be tentatively identified by morphology, providing potential sentinel early-warning systems for harmful blooms in coastal waters. Systems could be imagined that would alert experts to the presence of unknown biodiversity, indicative of new or invasive species. Size spectra of non-living particles and marine snow can be used to calculate vertical flux of material in the oceans. Many towed, moored, and drifting imaging systems have been developed in recent years for these purposes. These sensor systems are relatively complex compared to many physical and chemical sensors. They have high power requirements for illumination light sources, optical detectors, and computation, and require high bandwidth and/or data storage for the digital images
\end{abstract}

themselves. High-powered image analysis and classification algorithms are needed to convert the high volume of digital image data to significant knowledge about the distributions and size spectra of the particles/organisms. We believe this technology will be important for monitoring ocean health in the future, and significant development effort is needed to make these systems more practical and robust for the coming ocean observing systems. This has been the focus of a recently-formed SCOR (Scientific Committee on Oceanic Research) Working Group (WG 130). This white paper will describe the state-ofthe-art and indicate best avenues for rapid, efficient development of the technology with specific application for ocean observing.

\section{INTRODUCTION}

Plankton form the base of the marine food chain; link the atmosphere and deep ocean elemental fluxes, processes, and cycles; and can cause invasions and blooms that are harmful to marine ecosystems and humans. Plankton are intimately associated with the biochemistry of the ocean and can act as sentinel organisms as ocean properties, such as temperature, acidity, and chemical composition, change over time. As human population increases and environmental pressures reach the global level, the response and health of ocean ecosystems will become more critical 
to the sustainability of Earth. Historically, ocean observing systems have monitored physical and chemical properties, with biological measurements limited to simple proxies such as turbidity and chlorophyll fluorescence. Current and future ocean observing systems will need to monitor plankton communities.

Monitoring plankton is challenging. Communities are diverse and dynamic. Populations at a particular location come and go on short time intervals. Populations form patches at multiple scales and in three dimensions due to stratification, shear, and advection, as well as growth, grazing, and sinking. Plankton imaging and analysis systems have been developed to identify and enumerate living (plankton) and non-living particles in natural waters [1]. Digital image data can be analyzed to reveal abundances, size spectra, and biomass distributions of planktonic organisms as well as non-living particles. Detrital aggregates, or marine snow, are composed of living and non-living particle matter and play important roles in the time-variable export, regeneration and deep-water delivery of carbon and nitrogen. In-situ particle and plankton imaging and analysis systems provide a technique for examining the size spectra of these fragile and patchy aggregates, and facilitate the quantitative examination of aggregate shape, sinking rate and composition over large ocean areas [2], [3], [4], [5] and [6].

In many cases, abundance and taxonomic information is needed at the genus or species level. The zooplankter Calanus, for example, is an oil-rich copepod and its dense aggregations form a key food source for migrating baleen whales. Certain dinoflagellate species produce potent neurotoxins that can accumulate in shellfish and sicken or kill fish, marine mammals, and humans when eaten. Ideally, automated instruments would be able to recognize specific types of particles and organisms at fine taxonomic resolution, and under different environmental conditions, from oligotrophic blue waters to hypereutrophic coastal waters. Recognition of phytoplankton (e.g. [7], Fig. 1), zooplankton [8 and 9]), and ichthyoplankton to the family, or even genus level is currently possible in many cases [10]. Recognition at higher levels (e.g. functional groups), combined with morphometric features to estimate biomass, is useful for food web and ecosystem modeling [11 and 12].

\section{STATE OF THE ART}

Planktonic organisms smaller than about $20 \mu \mathrm{m}$ (protists and prokaryotes) generally have simple shapes (e.g. round, oblong, or filamentous) that are not useful to discriminate taxa. For larger planktonic organisms, morphology is the traditional taxonomic descriptor with greater discriminating power. Morphology can be captured in digital images. Rapid advances are being made in electro-optical technology, resulting in new and better ways of illuminating, detecting, and imaging plankton in situ. Prototype or commercially available high-resolution imaging and analysis systems now exist that detect plankton across a wide range of size scales [13], [14] and [15]. The hardware technology of these instruments is maturing.

Data analysis and software systems are not as mature as the hardware technology for plankton imaging. Typically, images are collected and then either stored or transmitted with minimal real-time analysis. Image collections are subsequently analyzed for abundances, particle/organism size, and identification. Automatically discriminating types of organisms from images is challenging. Small differences in illumination can yield large differences in image quality, so images taken from different instruments are difficult to compare quantitatively. Orientation of the organism in the image can induce large differences in the imaged structure. In the typical development path, experts classify a subset of images of organisms into classes that can be morphotypes and/or taxonomic categories. This set of expertclassified images forms a training set against which classification algorithms can be developed and tested. A full classifier scheme must include a number of elements: the training set; image analysis methods such as image correction, segmentation and feature extraction; and a classification algorithm, such as neural network, support vector machine, or decision tree; or an ensemble of algorithms. Independent quantification of error rates is also desirable for many applications. General training sets of expert-classified plankton images may not be practical since previous work suggests they must be different for differing imaging systems, and must be specific to a certain plankton community composition, or set of target organisms encountered. It has been shown that taxonomic experts are not unanimous, even when considering images of organisms with relatively distinct morphology [16]. The state of the art for automated image classifiers for a 10 - 30 class problem is $70-80 \%$ accuracy [17]. This is approaching the level of agreement among human experts. Bias due to errors in classification can be statistically corrected if the prior probabilities of the occurrences of the types are known [18]. A carefully collected expert-derived training set can provide these prior probabilities. Misclassification may also be reduced by considering results from multiple classifier approaches [9], or optimizing class 

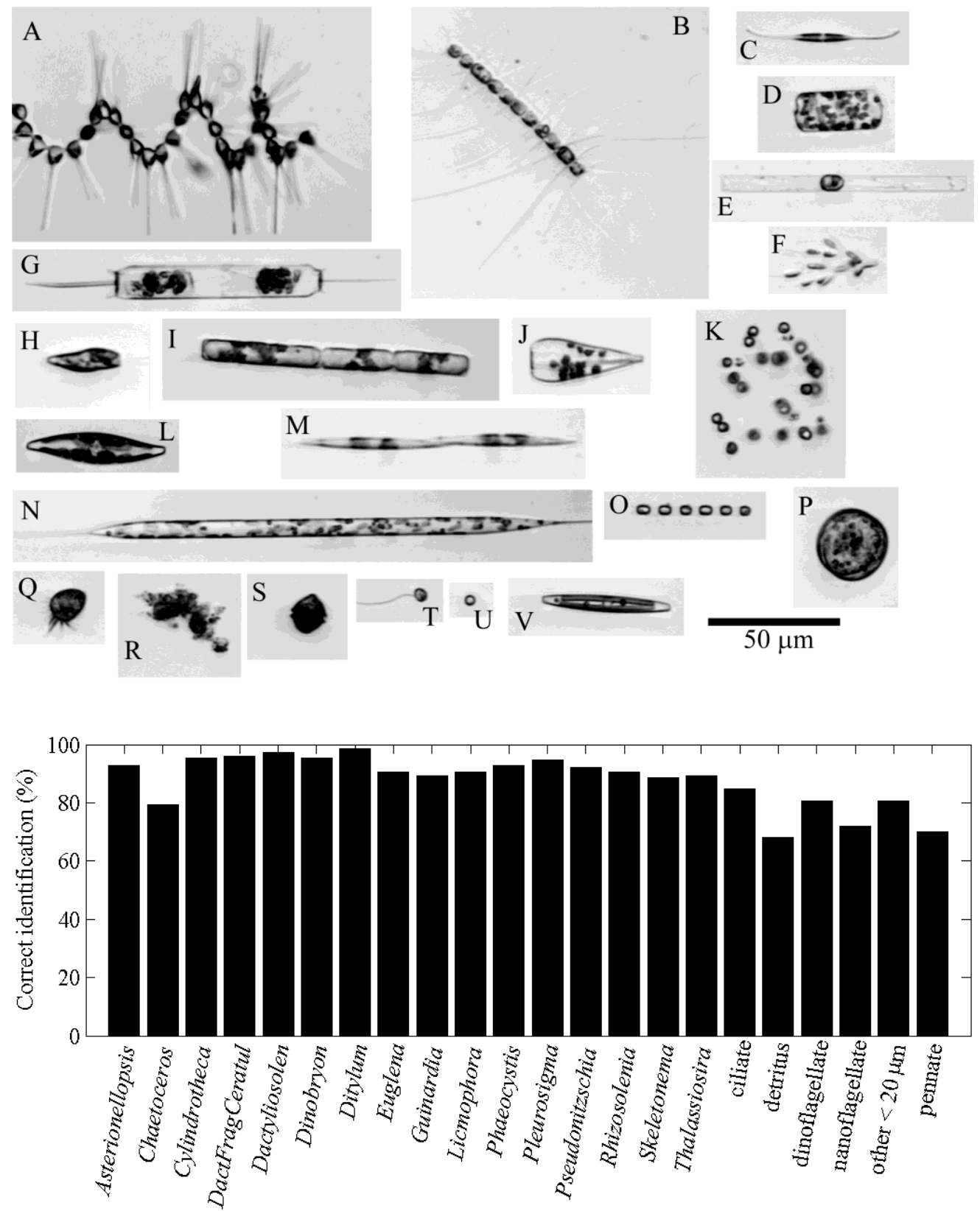

Figure 1. Example images and automated classification results for 22 categories identified from Imaging FlowCytobot observations in Woods Hole Harbor. Most categories are phytoplankton taxa at the genus level: Asterionellopsis spp. (A); Chaetoceros spp. (B); Cylindrotheca spp. (C); Ceratulina spp. plus the

morphologically similar species of Dactyliosolen such as D. fragilissimus $(D)$; other species of Dactyliosolen morphologically similar to D. blavyanus (E); Dinobryon spp. $(F)$; Ditylum spp $(G)$; Euglena spp. plus other euglenoids (H); Guinardia spp. (I); Licmophora spp. (J); Phaeocystis spp. (K);

Pleurosigma spp. (L); Pseudonitzschia spp. (M); Rhizosolenia spp. and rare cases of Proboscia spp. $(N)$; Skeletonema spp $(O)$; Thalassiosira spp. and similar centric diatoms $(P)$. The remaining categories are mixtures of morphologically similar particles and cell types: ciliates $(Q)$; detritus $(R)$; dinoflagellates > $20 \square m$ (S); nanoflagellates (T); other cells $<20 \square m(U)$; and other single celled pennate diatoms $(V)$. Reproduced from Sosik and Olson (2007). 
selection (Fig. 2 and [19]). More work on handling the errors in classification, and on tools and protocols for creating appropriate and unbiased training sets is needed.

\section{INTEGRATION TO OCEAN OBSERVING SYSTEMS}

Ocean observing systems must include plankton imaging instruments. These instruments have proven powerful in many biological oceanographic applications. They have been used for phytoplankton, zooplankton, marine snow particles, and metazoans including invertebrates and eggs, larvae, and adults of fish. Recent progress with plankton imaging instruments and associated analysis software has been reviewed [1] and [20]. Some instruments view an illuminated volume of relatively undisturbed water, while others pump water into a defined view area (imaging-in-flow). Instruments have been deployed from ships, either in towed, or vertical profiling modes. They have been deployed on remotely operated vehicles (ROVs), fixed moorings, Lagrangian floats, and autonomous underwater vehicles (AUVs). These diverse platforms, all capable of accommodating plankton imaging and analysis instruments, will be important components of future ocean observing systems.

Plankton imaging and analysis instruments are complex compared to many marine optical sensors (e.g. fluorometers and turbidity meters), but they provide a more direct measure of plankton (and other particulate material), and much more morphological and taxonomic information. There are a variety of optical sensors that measure proxies of plankton or particle load, such as light scattering, beam attenuation (transmittance), and chlorophyll fluorescence. Acoustic sensors can measure sonic backscattering from plankton and fish. Direct imaging systems deployed in strategic ways within ocean observing systems can serve to validate and expand interpretation of data from proxy sensors, which are typically smaller in size, cost, and power demand and thus can be deployed more widely in space and time. New lowpower digital holographic systems [21] and [22] are being integrated into oceanic profiling floats creating the potential for remote sampling of plankton taxa throughout the world ocean.

Many harmful algal species can be identified by morphology, so cell imaging has the potential to provide sentinel early-warning systems for harmful blooms in coastal waters [23]. Often the critical abundance of a HAB species can be very low (less than
10 individuals per cubic meter), making it difficult to collect sufficient specimens for training a classifier.

\section{CHALLENGES/FUTURE}

There are several hardware challenges with integrating plankton imaging instruments into ocean observing systems. The development of compact in-situ optical sensors capable of discriminating target particles against a high background of non-target particles suspended in the water column is one of the most demanding tasks in coastal regions. In the oceanic realm, where phyto- and zooplankton densities are usually low, the challenge is to synoptically observe a large volume of water with a sufficiently broad depth of focus, rather than scanning small volumes over time. In either case, sensors need to resolve a wide plankton size spectrum, from microbes to large crustaceans and fish larvae. The use of spatial filters and other optical signal processors such as those suggested by [24] may help to achieve such capabilities. In current systems illumination, camera, onboard logic, and data storage consume significant power compared to other simpler in-situ instruments. Engineering to reduce power consumption will be an ongoing effort.

Coccolithophorids, a particular group of nanophytoplankton, produce carbonate shells with particular birefringence properties. These organisms may be particularly susceptible to ocean acidification. Imaging of birefringence patterns can distinguish these cells (Fig. 3) and it is possible to imagine in situ instruments optimized to detect and monitor populations of coccolithophorids.

Like all optical instruments (indeed, virtually all in-situ sensors), surface biofouling can degrade performance during long-term deployments. These problems are being addressed by placing copper sources near the optical surfaces, mechanical shutters, or cleaning mechanisms. Optimal design issues include whether to put more computer logic closer to the imager for "smart" image digitization, or more removed from the sensor for post-acquisition processing. Placing computer logic near the sensor is needed, for example, to compress the images for efficient storage and transmission. In a sentinel system for harmful algae, it might be necessary for recognition of target species to be done at the sensor in real-time. Full real-time image recognition for complex planktonic communities on a remote platform is a primary goal for hardware and software development. Progress has been made in realtime recognition of fish eggs from natural waters [25]. Continued work to 

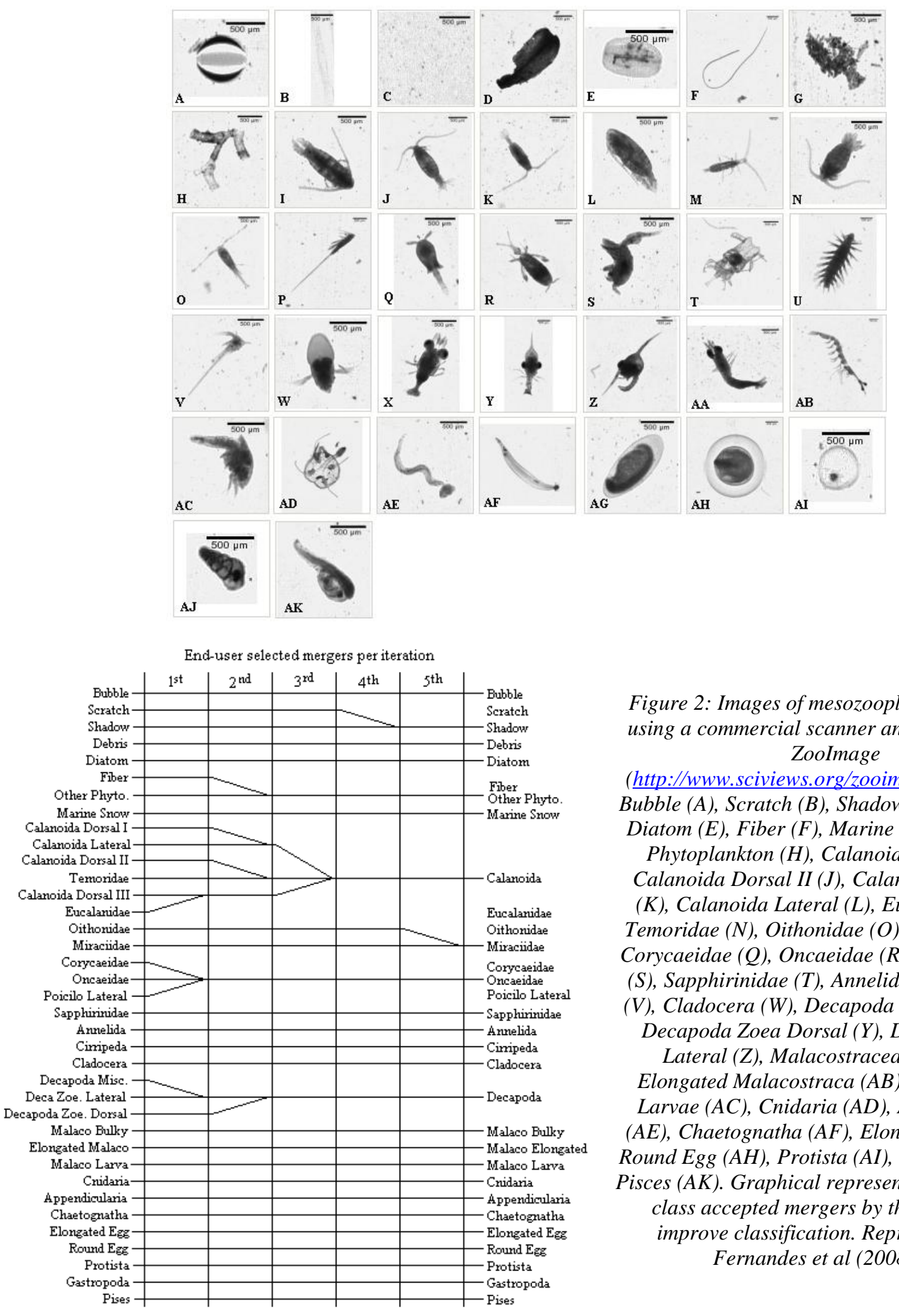

Figure 2: Images of mesozooplankton obtained using a commercial scanner and extracted with ZooImage

(http://www.sciviews.org/zooimage/index.html). Bubble (A), Scratch (B), Shadow $(C)$, Debris $(D)$, Diatom $(E)$, Fiber $(F)$, Marine Snow $(G)$, Other

Phytoplankton (H), Calanoida Dorsal I (I),

Calanoida Dorsal II (J), Calanoida Dorsal III

(K), Calanoida Lateral (L), Eucalanidae (M),

Temoridae (N), Oithonidae $(O)$, Miraciidae $(P)$,

Corycaeidae (Q), Oncaeidae (R), Poicilo Lateral

(S), Sapphirinidae (T), Annelida (U), Cirripeda

(V), Cladocera (W), Decapoda Miscelaneus (X),

Decapoda Zoea Dorsal (Y), Decapoda Zoea

Lateral (Z), Malacostracea Bulky (AA),

Elongated Malacostraca (AB), Malacostraca

Larvae (AC), Cnidaria (AD), Appendicularia

(AE), Chaetognatha (AF), Elongated Egg (AG),

Round Egg (AH), Protista (AI), Gastropoda (AJ),

Pisces (AK). Graphical representation of different class accepted mergers by the end-user to improve classification. Reproduced from Fernandes et al (2008) [19] 


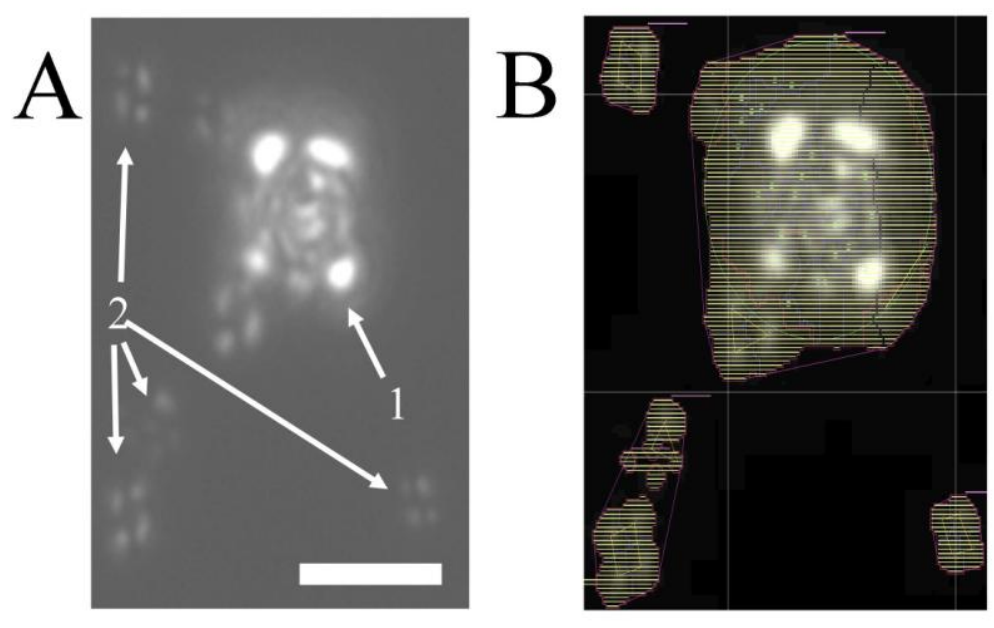

Figure 3. Coccolithophores are calcifying algae found throughout the world ocean which have great biogeochemical relevance due to their calcium carbonate coccoliths which contribute $25 \%$ of all marine sediments. Automated means to define and enumerate them are critical. A) Microscopic birefringence image of plated coccolithophore (1) and detached coccoliths (2) in seawater sample from the Gulf of Maine, viewed under cross-polarized light. Plated coccolithophores appear as round groups of white dots against a dark field whereas individual coccoliths appear as groups of four symmetric dots in this image. Scale bar is $5 \mu \mathrm{m}$. B) Results of classification algorithm CCC (free coccoliths, plated coccolithophores and aggregates of coccoliths), which identifies and enumerates free coccoliths, plated coccolithophores and aggregates of coccoliths based on their distinct birefringence patterns. A complete description of the algorithm will be published elsewhere.

identify features and create improved classification algorithms is needed. It has been suggested that a community effort of open source software development is the best way to make progress in this area (RAPID: Research of Automated Plankton Identification [1]). Examples of such software development are the Plankton Analysis System (PAS) and the Plankton Interactive Classification Tool (PICT) being developed at the University of Massachusetts Amherst [26]. PAS is a web-application that provides the functionality for experts to upload their images and algorithms, process images, hand-label exemplars, train classifiers and use those classifiers to automatically label new images. Zoo/Phytoimage has been successfully employed in a number of studies [12] and [27] as tool for automatic identification of scanned meso- and macrozooplankton images. More recently, a plugin has been developed to handle phyto- and microzooplankton images generated by the FlowCAM (Flow Cytometer And Microscope). An international SCOR working group is currently addressing the future development needs, such as standardization and specifications, of automated visual plankton identification (http://www.scor-wg130.net/). This attention to specifying comparable data sets and quality control methods is essential for plankton imaging to be incorporated into large scale ocean observing systems.
Ocean observing systems of the future will include plankton imaging and analysis instruments to monitor diversity and alert experts to unexpected, new, or invasive, taxa. They will be part of coastal sentinel systems providing early warning of harmful blooms. They will monitor the structure and health of marine food webs and provide insights into the productivity of marine ecosystems. They will help constrain particulate carbon fluxes along onshore-offshore gradients and vertical particle flux in the open ocean. Plankton imaging and analysis instruments will be key components of future coastal and oceanic ocean observing systems in their critical role of monitoring the health of marine ecosystems. A better understanding of the dynamics of ocean life will allow more rational management policies designed to protect the ocean and its life and, ultimately, ours.

\section{ACKNOWLEDGEMENTS}

Funding for MS, MB, AH, CP, and WB was provided by the collaborative NSF grant ATM-0325937. Funding for CD was provided by NOAA grant NA06OAR4170019. The Scientific Committee on Ocean Research (SCOR) Working Group \#130 funded workshops that motivated this paper. This paper is 
dedicated to Drs. Edward Riseman and Paul Utgoff whose ideas greatly contributed to this research.

\section{REFERENCES}

1. Benfield, M.C., Grosjean, P., Culverhouse, P., Irigoien, X., Sieracki, M.E., Lopez-Urrutia, A., Dam, H.G., Hu, Q., Davis, C.S., Hansen, A., Pilskaln, C.H., Riseman, E., Schultz, H., Utgoff, P.E. \& Gorsky, G. (2007), RAPID: Research on Automated Plankton Identification. Oceanography. 20(2), 12 - 26.

2. Gorsky, G., Aldorf, C., Kage, M., Picheral, M., Garcia, Y. \& Favole, J. (1992), Vertical Distribution of Suspended Aggregates Determined by a New Underwater Video Profiler. . Ann. Inst. Oceanogr. 68, 275-280.

3. Jackson, G.A., Maffione, R., Costello, R., Alldredge, A., Logan, B. \& Dam, H. (1997), Particle Size Spectra between $1 \mathrm{~mm}$ and $1 \mathrm{~cm}$ at Monterey Bay Determined Using Multiple Instruments. . Deep Sea Research Part I: Oceanographic Research Papers. 44, 1739-1767.

4. Pilskaln, C., Lehmann, C., Paduan, J. \& Silver, M. (1998), Spatial and Temporal Dynamics in Marine Aggregate Abundance, Sinking Rate, and Flux: Monterey Bay, Central California. Deep Sea Research Part II. 45, 1803-1837.

5. Pilskaln, C.H., Villareal, T.A., Dennett, M., DarkangeloWood, C. \& Meadows, G. (2005), High Concentrations of Marine Snow and Diatom Algal Mats in the North Pacific Subtropical Gyre: Implications for Carbon and Nitrogen Cycles in the Oligotrophic Ocean. Deep-Sea Research Part I: Oceanographic Research Papers. 52(12), 2315-2332.

6. Checkley, D.M., Davis, R.E., Herman, A.W., Jackson, G.A., Beanlands, B. \& Regier, L.A. (2008), Assessing Plankton and Other Particles in Situ with the SOLOPC. Limnol. and Oceanogr. 53, 2123-2136.

7. Sosik, H.M. \& Olson, R.J. (2007), Automated Taxonomic Classification of Phytoplankton Sampled with Imagingin-Flow Cytometry. Limnol. and Oceanogr. Methods. 5, 204-216.

8. Davis, C.S., Hu, Q., Gallager, S.M., Tang, X. \& Ashjian, C.J. (2004), Real-Time Observation of Taxa-Specific Plankton Distributions: An Optical Sampling Method. Mar. Ecol. Progr. Ser. 284, 77-96.

9. Hu, Q. \& Davis, C. (2006), Accurate Automatic Quantification of Taxa-Specific Plankton Abundance Using Dual Classification with Correction. Mar. Ecol. Progr. Ser. 306, 51-61.

10. Grosjean, P., Picheral, M., Warembourg, C. \& Gorsky, G. (2004), Enumeration, Measurement, and Identification of Net Zooplankton Samples Using the Zooscan Digital Imaging System. ICES J. Mar. Sci. 61, 518-525.

11. Irigoien, X., Fernandes, J., Grosjean, P., Denis, K., Albaina, A. \& Santos, M. (2009), Spring Zooplankton Distribution in the Bay of Biscay from 1998 to 2006 in Relation with Anchovy Recruitment. J. Plankton Res. 31, 1-17.
12. Zarauz, L., Irigoien, X. \& Fernandes, J.A. (2008), Modelling the Influence of Abiotic and Biotic Factors on Plankton Distribution in the Bay of Biscay, During Three Consecutive Years (2004-06). Journal of Plankton Research. 30(8), 857-872.

13. Davis, C.S., Thwaites, F.T., Gallager, S.M. \& Hu, Q. (2005), A Three-Axis Fast-Tow Digital Video Plankton Recorder for Rapid Surveys of Plankton Taxa and Hydrography. Limnol. and Oceanogr. Methods. 3, 5974.

14. Olsen, R.J. \& Sosik, H.M. (2007), A Submersible Imaging-in-Flow Instrument to Analyze Nano- and Microplankton: Imaging Flowcytobot. Limnol. and Oceanogr. Methods. 5, 195-203.

15. Dominguez-Caballero, J., Loomis, N., Li, W., Hu, Q., Milgram, J., Barbastathis, G. \& Davis, C. (2007), Advances in Plankton Imaging Using Digital Holography. In: Adaptive Optics: Analysis and Methods/Computational Optical Sensing and Imaging/Information Photonics/Signal Recovery and Synthesis Topical Meetings on CD-ROM, OSA Technical Digest (CD) (Optical Society of America), paper DMB5.

16. Culverhouse, P.F., Williams, R., Reguera, B., Herry, V. \& González-Gil, S. (2003), Do Experts Make Mistakes? A Comparison of Human and Machine Identification of Dinoflagellates. Mar. Ecol. Progr. Ser. 247, 17-25.

17. Blaschko, M., Holness, G., Mattar, M., Lisin, D., Utgoff, P., Hanson, A., Schultz, H., Riseman, E., Sieracki, M., Balch, W. \& Tupper, B. Automated In-situ Identification of Plankton. in IEEE Workshop on Applications in Computer Vision. 2005. Breckinridge, Colorado.

18. Solow, A.R., Davis, C. \& Hu, Q. (2001), Estimating the Taxonomic Composition of a Sample When Individuals Are Classified with Error. Mar. Ecol. Progr. Ser. 216, 309-311.

19. Fernandes, J.A., Irigoien, X., Boyra, G., Lozano, J.A. \& Inza, I. (2008), Optimizing the Number of Classes in Automated Zooplankton Classification. Journal of Plankton Research. 31(1), 19-29.

20. Wiebe, P.H. \& Benfield, M.C. (2003), From the Hensen Net toward Four-Dimensional Oceanography. Progress in Oceanography. 56, 7-136.

21. Loomis, N., Dominguez-Caballero, A., Li, W., Hu, Q. Davis, C., Milgram, J. \& Barbastathis, G. (2007), A Compact, Low-Power Digital Holographic Imaging System for Automated Plankton Taxonomic Classification. 4th Intl Zooplankton Symposium, Hiroshima, Japan.

22. Davis, C. (2008), Optical Imaging of Ocean Plankton: A Fantastic Voyage, in Digital Holography and ThreeDimensional Imaging. In: OSA Technical Digest (Optical Society of America, 2008), paper DMB1, 3pp. 
23. Campbell, L., Olson, R. \& Sosik, H. (2008), First Toxic Dinophysis Bloom Observed in the Gulf of Mexico, USA. HArmful Algae News. 36, 10-11.

24. Strickler, J. \& Hwang, J.-S. (1999), Matched Spatial Filters in Long Working Distance Microscopy of Phase Objects, in Focus on Multidimensional Microscopy, P.C. Cheng, et al., Editors, World Scientific Publishing Pte. Ltd.: River Edge, NJ. p. 217-239.

25. Iwamoto, S., Checkley, D.M. \& Trivedi, M.M. (2001), Reflics: Real-Time Flow Imaging and Classification System. Machine Vision and Applications. 13, 1-13.

26. Mattar, M., SJ, M. \& AR, H., Software Tools for Image Analysis, in Technical Report UM-CS-2009-017, Dept. of Computer Science, University of Massachusetts, Amherst. 2009, Dept. of Computer Science, University of Massachusetts,: Amherst, MA.

27. Bell, J.L. \& Hopcroft, R.R. (2008), Assessment of Zooimage as a Tool for the Classification of Zooplankton. J. Plankton Res. 30(12), 1351-1367. 